Eng. Appl. Sci. Lett., Vol. 1(2018), No. 2, pp. $30-36$

Website: https://pisrt.org/psr-press/journals/easl/

ISSN: 2617-9709 (Online) 2617-9695 (Print)

http://dx.doi.org/10.30538/psrp-easl2018.0009

\title{
ISOLATION, PURIFICATION AND COMPLEX FORMATION OF NICOTINE ALKALOID
}

\author{
SAJID MAHMOOD ${ }^{1}$, SAIQA JAMEEL, ZAHEER AHMAD
}

\begin{abstract}
Nicotiana tabacum is rich with medicinal importance. The aim of the study is to isolate, purify and compare nicotine (3-[1-Methylpyrolidine2 -yl] pyridine) from different brands of cigarettes. Isolation is carried out by liquid-liquid extraction using ether as solvent. Crude nicotine samples are further purified with SPE (solid phase extraction) method. Nicotine crystals are complexed with zinc chloride $\left(\mathrm{ZnCl}_{2}\right)$. Fine and pure crystals of metal complexes are obtained with Nic-C and Nic-D. However, no complex formation is synthesized with Nic-A and Nic-B due to impurities in the sample which is confirmed by thin layer chromatography. Antibacterial activity of the samples is carried out against different strains of bacteria which showed positive results for Nic-C and Nic-D. The outcomes of the study reveal that Zinc-Nicotine complexes can be used as therapeutic agents and anti-sickness agents in sickle cell disease.
\end{abstract}

Index Terms: Nicotine; solvent extraction; Zn-nicotine complex; antisickness; therapeutic agent.

\section{Introduction}

Nicotiana tabaccum, is a stout herbaceous plant in the solanaceae family that originated in the tropical Americas and now cultivated worldwide [1. It is the commercial source of tobacco. It contain nicotine, a powerful neurotoxin that is particularly harmful to insects 2. Nicotine, a carcinogen, is the compound responsible for the addictive nature of tobacco use [3]. Nicotine is also used as insecticides. Structure of nicotine is shown in Figure 1.

Received 09-7- 2018. Revised 12-8-2018. Accepted 12-9-2018

1 Corresponding Author

(c) 2018 Sajid Mahmood, Saiqa Jameel, Zaheer Ahmed. This is an open access article distributed under the Creative Commons Attribution License, which permits unrestricted use, distribution, and reproduction in any medium, provided the original work is properly cited. 


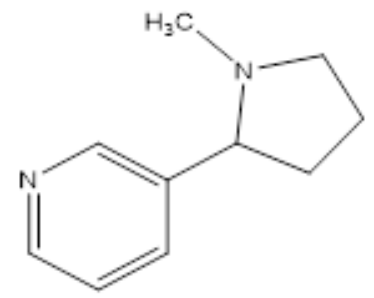

Figure 1. Structure of nicotine

It was observed by literature that nicotine could be extracted by different techniques. Nicotine and zinc are closely related to a variety of brain pathologies, including schizophrenia, anxiety, depression, Parkinson's and Alzheimer's diseases 4. Yuegang Zuo developed ultrasonic extraction (UE) of nicotine with heptane followed by direct capillary gas chromatography (GC) separation [5. Lubomir Svorc developed a sensitive, selective and reliable electrochemical method for the determination of nicotine using differential pulse voltammeter on a bare boron-doped diamond electrode [6. We have used the technique which is not used in previous studies. Our method is more economical and convenient. Nicotine was isolated from the seeds of N. tabacum and its Zinc (II) complex was synthesized [7] and now in the present study, nicotine is isolated from different brands of cigarettes and its Zinc complexes are synthesized and bacterial sensitivity against different micro-organisms were performed. The outcomes of the study reveal that Zinc-Nicotine complexes can be used as therapeutic agents and anti-sickness agents in sickle cell disease.

\section{Materials and Methods}

Aluminum sheets pre-coated with silica gel $\left(60 F_{254}\right)$, chloroform, ether, distilled water, saturated picric acid solution, Methanol, $5 \% \mathrm{NaOH}$ solution, $\mathrm{ZnCl}_{2}$, and dimethylsulphoxide, R.B flask, separating funnel, Whatman filter paper no.1, are used throughout the study. Label information of five different brands of cigarette is given in Table 1 .

\section{Experimental Work}

In-vitro evaluation of nicotine is carried out from different brands of cigarettes in local market of Lahore, Pakistan. The simple extraction method is subject to isolate the nicotine alkaloid from its source.

3.1. Isolation of Nicotine from Cigarette. $10 \mathrm{~g}$ of cigarette leaves are taken in a beaker, added $100 \mathrm{~mL}$ of $5 \% \mathrm{NaOH}$ solution and stirred it for half hour on hot plate. Filtered it by using glass wool and transferred the cigarettes again to beaker. Added $30 \mathrm{~mL}$ distilled water and stirred and filtered again. Collected the filtrates together and transferred to separating funnel. Extracted the nicotine by $30 \mathrm{~mL}$ ether and repeated the extraction 3 times. Gathered the four filtrates in a conical flask and evaporated ether on water bath. Added $4 \mathrm{~mL}$ methanol to 
TABLE 1. Label information of five different brands of cigarette

\begin{tabular}{|l|l|l|l|l|l|}
\hline $\begin{array}{l}\text { Sr. } \\
\text { No. }\end{array}$ & $\begin{array}{l}\text { Brand } \\
\text { Name }\end{array}$ & Abbreviation & Company & $\begin{array}{l}\text { Price } \\
/ \text { Cig }\end{array}$ & $\begin{array}{l}\text { Total } \\
\text { Price } \\
/ 20 c i g\end{array}$ \\
\hline 1 & Prime & Nic-A & $\begin{array}{l}\text { Flacon Cigarette } \\
\text { Industry }\end{array}$ & 2 & 42 \\
\hline 2 & Cafe & Nic-B & $\begin{array}{l}\text { Universal Tobacco } \\
\text { Company }\end{array}$ & 2.5 & 50 \\
\hline 3 & Classic & Nic-C & $\begin{array}{l}\text { National Tobacco } \\
\text { Industries }\end{array}$ & 3 & 58 \\
\hline 4 & Dunhill & Nic-D & $\begin{array}{l}\text { Dunhill Tobacco of } \\
\text { London Limited }\end{array}$ & 7.5 & 150 \\
\hline
\end{tabular}

dissolve the resulted oil. Pure nicotine is derived subsequently and then dissolved in another solvent such as ether and small amount of n-hexane was added for recrystallization.

3.2. Characterization of Pure Nicotine. Digital melting point apparatus is used to determine melting points of different extracted pure samples (after SPE Purification). The average melting point of the samples was $-79 C^{0}$. Thin layer chromatography is subjected to check the specificity and purity of nicotine in all brands by using solvent system n-butanol: acetic acid: water $(3: 1: 1 \mathrm{v} / \mathrm{v})$ and compared it by Co-TLC with the standard. It was found that the nicotine in all the brands showed single spot $\left(R_{f}\right.$ values 0.47$)$ after visualization on TLC plate which confirmed the purity and specificity of the nicotine and it is also noted that no interference of any component on TLC observed (Table 2). FT-IR spectroscopy was used for IR-spectrum of extracted purified nicotine i.e. shown in Table 3. By using an UV-absorption spectrophotometer, absorption spectrum of extracted purified crystalline nicotine is taken at different absorbance against different wavelength. The $\lambda_{\max }$ was found to be $760 \mathrm{~nm}$.

TABle 2. Characteristics of purified Nicotine isolated from Cigarettes

\begin{tabular}{|l|l|l|l|}
\hline Sample & $\begin{array}{l}\text { Melting Point } \\
\left(C^{0}\right)\end{array}$ & $\begin{array}{l}\lambda_{\max } \\
(\mathrm{mn})\end{array}$ & $R_{f}$ \\
\hline Nic-A & -80 & 759 & 0.46 \\
\hline Nic-B & -78 & 758 & 0.48 \\
\hline Nic-C & -79 & 760 & 0.47 \\
\hline Nic-D & -79 & 760 & 0.47 \\
\hline
\end{tabular}

3.3. Complex Formation. Nicotine isolated from leaves of Nicotiana tabacum is used for complexation with $Z n$ and is studied for their antibacterial activities 
TABLE 3. Characteristics IR-absorption bands of samples

\begin{tabular}{|l|l|l|l|l|}
\hline Bond & $\begin{array}{l}\mathrm{v}\left(\mathrm{cm}^{-1}\right) \\
\text { Nic-A }\end{array}$ & $\begin{array}{l}\mathrm{v}\left(\mathrm{cm}^{-1}\right) \\
\text { Nic-B }\end{array}$ & $\begin{array}{l}\mathrm{v}\left(\mathrm{cm}^{-1}\right) \\
\text { Nic-C }\end{array}$ & $\begin{array}{l}\mathrm{v}\left(\mathrm{cm}^{-1}\right) \\
\text { Nic-D }\end{array}$ \\
\hline CH (Stretching) & 2964 & 2963 & 2968 & 2970 \\
\hline C=N & 1673 & 1674 & 1676 & 1677 \\
\hline C=C & 1689 & 1689 & 1690 & 1691 \\
\hline CH (Bending) & 902 & 901 & 903 & 904 \\
\hline
\end{tabular}

against different strains of gram positive and gram-negative bacteria compared it with Zinc salt $\left(\mathrm{ZnCl}_{2}\right)$ used for complexation and nicotine alone.

3.3.1. Complex Formation of Nicotine. $0.1 \mathrm{~g}$ of sample is dissolved in $15 \mathrm{~mL}$ methanol in round bottom flask and stirred for 5 minutes. Then $0.5 \mathrm{~g}$ of metal salt $\mathrm{ZnCl}_{2}$ is dissolved in it. Then refluxed it for one hour, and separated it by adding $10 \mathrm{~mL}$ of chloroform in separating funnel. Separated the lower layer of chloroform and placed it for evaporation. Fine and pure crystals of metal complex are obtained. Structure of zinc-nicotine complex is shown in Figure 2.

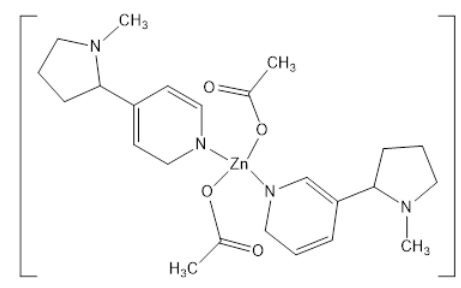

Figure 2. Structure of zinc-nicotine complex

3.3.2. Identification of Complex Formation. TLC is checked to confirm the synthesis of complex compounds Nic-A, Nic-B, Nic-C and Nic-D. The compounds Nic-A and Nic-B did not show a single spot on precoated aluminum silica gel plate which confirmed the impurities in the sample A and B. It is concluded that no complex formation is done by these compounds. The compounds Nic-C and Nic-D showed single spot on TLC cards which confirmed the complex formation by these compounds.

\section{Antibacterial Activity of Nicotine}

4.1. Preparation of stock solutions. Stock solutions of all the test samples in the concentration of $1 \mathrm{mg} / \mathrm{mL}$ are prepared in dimethylsulphoxide and then diluted to 100 and $200 \mathrm{~g} / \mathrm{mL}$ with the same solvent.

4.2. Inhibition assay. The anti-microbial sensitivity tests of the title compounds are tested against ten different species of gram positive and gramnegative bacteria. The compounds are used in two concentrations that is, 100 
$\mu \mathrm{g} / 100 \mu \mathrm{L}$ (first dose level) and $200 \mu \mathrm{g} / 100 \mu \mathrm{L}$, the second dose level. The antibacterial activities of nicotine and its zinc complex are determined by 'Agar Well Diffusion Method' proposed by [8]. According to this method, the weighed components of the dehydrated medium are dissolved in distilled water and made the volume to one liter. Solution was heated till boiling for complete dissolution of the components. The medium is autoclaved at the pressure of $15 \mathrm{Ibs} / \mathrm{in} 2$ for $15 \mathrm{~min}$ while keeping the temperature of $121 \mathrm{C}$. The autoclaved medium is then poured in the sterile Petri plates and was allowed to solidify in the clean environment. Then these plates are incubated at $37 \mathrm{C}$ for $24 \mathrm{~h}$ to check their sterility.

4.3. Measurement of Antibacterial Activity. One loop, full of $24 \mathrm{~h}$ old bacterial culture containing approximately 104 to $106 \mathrm{CFU}$, was spread on the surface of Mueller-Hinton agar plates. The composition of Mueller-Hinton agar medium is given in Table 1 . Wells were dug in the medium with the help of sterile metallic borer. The marked area is filled with diluted solutions of the test samples, metal salts and solvent dimethylsulphoxide. These plates are incubated at $37 \mathrm{C}$ for $24 \mathrm{~h}$. At the end of the incubation period, the inhibition zones are measured to the nearest millimeters. Antibacterial activity is indicated by a clear zone encircling the marked area. Beyond the marked area, there is a homogenous confluent lawn of bacterial growth.

\section{Results and Discussion}

In our present study, four different brands of cigarettes i.e., Nic-A, Nic-B, Nic$\mathrm{C}$ and Nic-D of four different companies $\mathrm{W}, \mathrm{X}, \mathrm{Y}$ and $\mathrm{Z}$ are used. The basic compound (Nicotine) in all the cigarettes was same with slight variation in complexation. Our first attempt was to extract and purify the nicotine alkaloid by using simple solvent extraction method and compare them to each other and with standard for qualitative analysis. Using the experimental observations, it is found that Nic-A is extracted by weight as $1.75 \mathrm{gm}$ in amorphous powder; Nic-B is extracted by weight as $1.46 \mathrm{gm}$, Nic-C $1.07 \mathrm{gm}$ and Nic-D $0.87 \mathrm{gm}$ as fine crystals respectively.

Further the compounds are used for metal complexes, four of which, two compounds Nic-A and Nic-B could not be subjected for complex formation because of impurities were present in them, (checked by TLC with the standard). The compounds Nic-C and Nic-D are used for Zn-nicotine complex due to its purity and fine crystals. From the results and plots it is also observed and concluded that the products of company $\mathrm{Y}$ and $\mathrm{Z}$ have been better qualified than the products of company $\mathrm{W}$ and $\mathrm{X}$. In nicotine structure due to the presence of nitrogen atom it has unsymmetrical divergent ligand property.

Here only the antimicrobial properties are discussed with reference to the standard. The antimicrobial activity of Zn-II-nicotine complex is tested against Gram negative and Gram-positive bacteria. The concentrations of the compounds are used that is $100 \mu \mathrm{g} / 100 \mu \mathrm{L}$ and $200 \mu \mathrm{g} / 100 \mu \mathrm{L}$ for first dose level and 
second dose level. Results of Zn (II)-nicotine complex for both the concentrations are given in Table 5.

\section{Qualitative Analysis of Nicotine}

The weight of Nicotine in four different brands of cigarettes is given in Table 4 and comparison between amounts of nicotine in different brands is shown in Figure 3.

TABLE 4. The weight of Nicotine in four different brands of cigarettes

\begin{tabular}{|l|l|l|l|l|}
\hline Sample & $\begin{array}{l}\text { Amount of sample } \\
(\mathrm{g})\end{array}$ & $\begin{array}{l}\text { Amount of } \\
\text { Nicotine } \\
\text { after solvent } \\
\text { extraction } \\
(\mathrm{mg})\end{array}$ & $\begin{array}{l}\text { \%age } \\
\text { of Nicotine } \\
\text { before SPE }\end{array}$ & $\begin{array}{l}\text { \%age } \\
\text { of Nicotine } \\
\text { after SPE }\end{array}$ \\
\hline Nic-A & 10 & 1.75 & 0.0175 & 0.0125 \\
\hline Nic-B & 10 & 1.46 & 0.0146 & 0.0100 \\
\hline Nic-C & 10 & 1.07 & 0.0107 & 0.0098 \\
\hline Nic-D & 10 & 0.87 & 0.0087 & 0.0077 \\
\hline
\end{tabular}

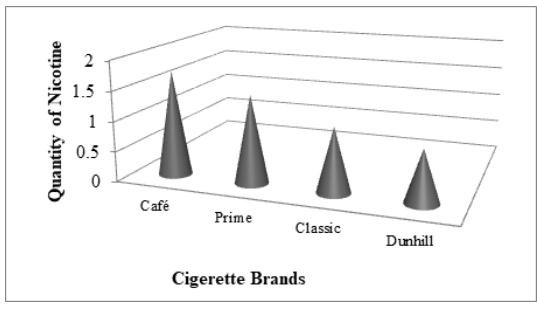

Figure 3. comparison between amounts of nicotine in different brands

The results reveal that nicotine is inactive for 1st dose level and is more effective antibiotic against 2nd dose level for Gram positive and Gram-negative bacteria i.e. S. faecalis and E. coli respectively. Zn-nicotine complex did not inhibit the both Gram negative and Gram-positive bacteria however, in the 2nd dose level; it inhibited the growth of both the bacterial species. The results are also compared with three antibiotics that is Gentamycin, Tetracycline, Tobramycin. On the basis of above evidences, we comment that this $\mathrm{Zn}$-nicotine complex is broad applicant antimicrobial agent and is active against Gram positive and Gram-negative bacterial species. Further, Zinc-Nicotine complexes can be used as therapeutic agents and anti-sickness agents in sickle cell disease.

\section{Competing Interests}

The authors do not have any competing interests in the manuscript. 
TABLE 5. Antimicrobial activity of Zn-II-nicotine complex

\begin{tabular}{|l|l|l|l|l|}
\hline $\begin{array}{l}\text { Sr. } \\
\text { No. }\end{array}$ & $\begin{array}{l}\text { Compound } \\
\text { used }\end{array}$ & $\begin{array}{l}\text { Conc. } \\
\mu \mathrm{g} / 100 \mu \mathrm{L}\end{array}$ & $\begin{array}{l}\text { Gram positive } \\
\text { organisms }\end{array}$ & $\begin{array}{l}\text { Gram negative } \\
\text { organisms }\end{array}$ \\
\hline \multirow{2}{*}{1} & Gentamycin & 100 & 31 & 35 \\
200 & 40 & 80 \\
\hline \multirow{2}{*}{2} & \multirow{2}{*}{ Tetracycline } & 100 & & 12 \\
& 200 & & 25 \\
\hline \multirow{2}{*}{3} & \multirow{2}{*}{ Tobramycin } & 100 & 30 & 30 \\
& 200 & 70 & 50 \\
\hline \multirow{2}{*}{4} & \multirow{2}{*}{ Nicotine } & 100 & & 14 \\
& & 200 & & 18 \\
\hline 5 & Zn-II-nicotine & 100 & 20 & 20 \\
\hline
\end{tabular}

\section{REFERENCES}

1. Ren, N., \& Timko, M. P. (2001). AFLP analysis of genetic polymorphism and evolutionary relationships among cultivated and wild Nicotiana species. Genome, 44(4), 559-571.

2. Ujváry, I. (1999). Nicotine and other insecticidal alkaloids. In Nicotinoid insecticides and the nicotinic acetylcholine receptor (pp. 29-69). Springer, Tokyo.

3. Munir, C., Zaidi, M. I., \& Yousaf, S. M. (1994). Zinc, cadmium and mercury as extractants of nicotine from tobacco leaves. Main Group Metal Chemistry, 17(9), 673-677.

4. Takeda, A., Tamano, H., Kan, F., Itoh, H., \& Oku, N. (2007). Anxiety-like behavior of young rats after 2-week zinc deprivation. Behavioural brain research, 177(1), 1-6.

5. Zuo, Y., Zhang, L., Wu, J., Fritz, J. W., Medeiros, S., \& Rego, C. (2004). Ultrasonic extraction and capillary gas chromatography determination of nicotine in pharmaceutical formulations. Analytica Chimica Acta, 526(1), 35-39.

6. Švorc, L., Stanković, D. M., \& Kalcher, K. (2014). Boron-doped diamond electrochemical sensor for sensitive determination of nicotine in tobacco products and anti-smoking pharmaceuticals. Diamond and Related Materials, 42, 1-7.

7. Grana, R., Benowitz, N., \& Glantz, S. A. (2014). E-cigarettes: a scientific review. Circulation, 129(19), 1972-1986.

8. Akhtar, N., Malik, A., Ali, S. N., \& Kazmit, S. U. (1992). Proceragenin, an antibacterial cardenolide from Calotropis procera. Phytochemistry, 31(8), 2821-2824.

Sajid Mahmood

Division of Science and Technology, University of Education, Lahore 54590, Pakistan.

e-mail: drsajidue@gmail.com

Saiqa Jameel

Division of Science and Technology, University of Education, Lahore 54590, Pakistan.

Zaheer Ahmed

Department of Chemistry, University of Wah, Wah Cantt, Pakistan. 